\title{
DE LA CÁBALA AL GOLEM MÁGICO
}

\author{
Kattia Chinchilla Sánchez
}

\begin{abstract}
RESUMEN
La Cábala práctica nos presenta un universo de reflexiones místicas, entre las cuales se destaca la preceptiva para la creación del Golem, un simulacro hecho por el hombre, que viene a constituirse en el doppelgänger de su hacedor, en una vía de expiación para la humanidad. Hemos de tratar aquí estos temas con el objeto de evidenciar cómo la criatura es concebida en el seno de la Cábala hebrea.
\end{abstract}

\begin{abstract}
The Kabbala shows to us a universe of mystic thoughts teaching all the precepts to create the Golem, an artificial man, maked by the rabbi with certain recipes. The Golem should be a doppelgänger of his maker, almost can be a general atonement way for the Jewish people. This article presents this topics related to the Practice Hebrew Kabbala and the Paracelsus homunculus theory.
\end{abstract}

\section{Por los senderos de la Cábala}

La Cábala es concebida como la doctrina mística de los hebreos y nace de las fuentes de conocimiento no siempre apegadas a la luz de la razón o la lógica; más bien, surge a partir de la revelación divina y la meditación interior. Por lo tanto, la Tora (la Ley) de Moisés es una epifanía de la deidad, el verbo de Dios, revelado a un mortal, por su voluntad expresa. Empero, en ella se hallan cifrados los trazos exactos de la Verdad Universal y es tarea de los estudiosos descubrir el intrincado tapiz de la prosa sagrada. Dada la estrecha relación dialógica entre el Ser Supremo y la raza humana, un preciso examen de las Escrituras se hace necesario y hasta obligatorio. Pero la exégesis no puede detenerse en lo inteligible, sino que su misión debe trascender más allá de lo evidente, haciendo eco de las palabras escuchadas por el propio Moisés:

Tú le hablarás y les irás poniendo mis palabras en su boca. Yo estaré en tu boca y en la suya, y os mostraré lo que debéis hacer (Éxodo 4,15 ).

Por estos fundamentos, se asevera que la Cábala es la "Ciencia de la Verdad".

El mensaje primario del Libro del Génesis es claro y directo: el universo es obra de un ser exclusivo y autócrata, quien ha delegado en otro ente -el hombre-, ciertamente 
también único e irrepetible, la facultad de proseguir la acción y la "administración" iniciadas por la deidad. Sin embargo, para llevar a cabo una misión de tanta envergadura, el hombre debe entrar en contacto perenne con su creador, para conocer sus prerrogativas, para conocer su deseo y para aprender a servirle de manera fiel. Este es, grosso modo, el leit motiv del Génesis, el cual repiten los libros restantes, mas lo desarrollan de forma disímil, según el argumento del texto.

No obstante, el hombre de la Cábala se percata de un cierto mensaje oculto, misterioso y cautivante; queda impresionado por la cantidad de ideas que contienen cada una de las letras, de las palabras, de los versículos y de los capítulos que lo conforman. Así, en el Zohar (el Libro del Esplendor) (1982: 183) leemos:

\footnotetext{
¡Desgraciado el hombre que cree que la Escritura sólo nos enseña simples cosas! Porque cada palabra de la Escritura encierra un arcano esencial... Los misterios contenidos en la Escritura, con los cuales fueron creados todos los mundos, sólo podían descender a la tierra camuflados; porque el mundo material no puede soportar el brillo de todo aquello que es inmaterial (La traducción es nuestra).
}

El sentido literal de las sacras palabras carece de sentido, pues es una especie de envoltura, de ahí que en cierta ocasión el rey David dijera: "Levanta el velo que hay sobre mis ojos para que yo pueda contemplar las maravillas que encierra la ley" (2 Reyes 7, 21). Por desgracia, la primera letra del Libro del Génesis, beth, está cerrada por tres de sus lados y abierta por uno sólo, lo cual hizo suponer que el hombre únicamente dispone de ese pequeño acceso para penetrar en los secretos del mundo. Es obvio que estamos tratando con una imagen metafórica. Mediante el sibilino párrafo inicial, los hombres de la Cábala se referían al inicio del Génesis $(1,1)$ : "En el comienzo, Dios creó..." ("Breshit bara Elohim...", en hebreo) en donde la letra beth, la cual representa también el número dos, señala la existencia, en breshit, de dos elementos unidos, o bien cohesionados: uno que aparece claramente y otro rodeado por el misterio, una zona prohibida y tabuada, cuya frontera solamente puede ser traspasada por los elegidos.

\subsection{Origen ancestral}

Si incursionamos en la etiología de la práctica, notamos que los propios cabalistas se apegan a las más diversas e intrincadas hipótesis, todas ellas defendidas con pasión fiera. No obstante, hay un común denominador, a pesar de las opiniones diversas: los principios de la Cábala habrían sido adquiridos por los primeros hombres (homini religiosi), a partir del contacto con las entidades superiores, en definitiva, con Dios. Posiblemente, la postura más conocida y divulgada sea aquella según la cual el Zohar y otros textos básicos fueron dictados por un ser celestial, Raziel, el Ángel. Esta entidad habría entregado el primer libro cabalístico a Adán y, gracias a la sabiduría en él contenida, el padre de la humanidad pudo sobrellevar el dolor de la caída y el exilio definitivo de la tierra edénica.

En un antiquísimo texto hebreo, El Libro de la penitencia, se registra un hecho notorio: el mismo ángel guardián del Paraíso entregó a Seth, tercer hijo de Adán y Eva, las verdades fundamentales de la Cábala. En cambio, según el criterio de otros cabalistas, el Sefer Yetsira fue escrito por Abraham, considerado y laudado como el padre de la tradición nacional hebrea; inclusive habría aplicado la Tora antes de su promulgación en el Sinaí. En contraste 
con lo anterior, para otros, fue el profeta Elías quien reveló al Rabí Daniel de Provenza los principios de la sabiduría secreta.

Ahora bien, obviando tan profusas génesis, parece haber consenso al ubicar el origen de la práctica y la tradición cabalísticas en la época inmediatamente anterior al nacimiento de Cristo. Habiéndose producido la segunda destrucción del templo de Salomón en el año 7 de nuestra era, por intermedio de las legiones de Tito y habiéndose iniciado la diáspora judía, se produjo un progresivo alejamiento de la ley mosaica, que fue paulatinamente reemplazada por la Cábala. Supuestamente, siglos más, siglos menos, el Rabino Akiba escribió el Sefer Yetsira en este lapso y su discípulo Simon bar Juchai, el Zohar. Al margen de tratar de precisar las fechas y los autores, ambas obras son la primera concreción por escrito de los principios que hasta entonces los iniciados habían trasmitido en forma oral.

\subsection{La palabra y la escritura}

Como ya habíamos comentado líneas atrás, para los cabalistas, el Creador y los hombres han establecido fuertes vínculos dialógicos, pero llega un momento en el cual ya no son suficientes las palabras y es necesario un signo, una marca que fije en el pergamino el mandato que la voz no puede custodiar de una forma permanente. Así, la letra aparece para reforzar el valor del Verbo. La letra se hace memoria de la palabra. Desde esta perspectiva, el reinado de la palabra correspondió a un estado ideal del hombre, en el cual sus relaciones con la deidad se fundaban en la confianza mutua. Mas después del pecado (aún en la época pretoraica), el signo material, la letra, la Ot, tuvo que entrar a reforzar e incluso a reemplazar a la palabra. "El Señor puso una marca a Caín, para que no lo matara quien lo encontrase" (Génesis 4, 16). El Eterno necesitó de una señal para la frente del culpable: optó por un garabato delator.

A pesar de todo, los israelitas seguían creyendo en Dios y no tenían la necesidad imperiosa de una prueba escrita de sus divinos mandatos. Se daban por satisfechos con su Palabra. Empero, la actitud de los judíos que habían huido de la esclavitud egipcia fue muy diferente: quisieron pruebas concretas y fehacientes de la magnificencia de Dios. Así las cosas, el signo de Ot debió multiplicarse y el número de letras aumentó hasta constituir un corpus. El Hacedor dictó su alfabeto sagrado, sus 22 letras esenciales, sus 22 símbolos universales. El resultado fue que la Palabra se fijó por escrito en su propio detrimento, al someterse a las exigencias de la "historia". Si el hebreo venera la Santa Escritura es porque en ella percibe el mensaje de su Creador. La forma escrita no es sólo externa, sino que cada letra contiene fuerzas que sólo esperan ser liberadas.

El lector atento intentará, en la medida de sus posibilidades (las cuales, por obvias razones, siempre serán insuficientes), extraer las fuerzas arcanas animadoras de las letras, pues, cada una de ellas, al combinarse con otras, componen una palabra, cuyo sentido más oculto, cifrado y misterioso sólo puede dilucidarlo el cabalista mediante la separación o la reunión de esas letras sagradas. Más aún, con ellas estábase formando el Nombre Impronunciable, aquel que únicamente el Gran Sacerdote en la soledad del Sancta Sanctorum del Gran Templo podría pronunciar. Nótese a continuación la capital importancia otorgada a las letras:

Pues he aquí que la letra es un palacio y una fortaleza de la espiritualidad a la que apunta, y cuando un hombre menciona o mueve una de las letras, necesariamente se suscita esa espiritualidad. 


\begin{abstract}
Asimismo, suscítanse formas santas por obra del aliento de la boca, las que se elevan y unen entre sí por sus raíces dentro del dominio de la Emanación. Y no sólo esto, sino que también cobran existencia física; esto es, al escribirlas, sobre las letras se posa la espiritualidad (Cordobero 1977: 262).
\end{abstract}

En suma, este interés por la letra y por la escritura no fue patrimonio exclusivo de los cabalistas, sino afición compartida por todos los hebreos en general. El culto al libro se dio siempre a lo largo de su historia: según el Midrash Tehilim, desde el período de la esclavitud en Egipto, existía la costumbre de dedicar el día del Sabbat a la lectura. Como dato curioso, el Rabí Yehuda he-Hassid, en su Sefer Hassidim (Libro de los devotos) aconsejaba estrictamente a sus discípulos que, si por alguna desventura, caía una mancha de tinta en su libro y en sus vestiduras, debían de limpiar primero el libro y después lo demás. Inclusive añade que si dejaban caer oro y libros a la vez, recogerían en primer lugar el libro, luego el precioso metal. Una costumbre religiosa, cuya antigüedad no es posible determinar con certeza, prohibía destruir los libros, conducta que los cabalistas respetaron y ampliaron: se reunían los fragmentos de los textos inservibles y eran depositados en un lugar ex professo, en las sinagogas, para luego ser sepultados en un cementerio. Este singular entierro llevaba el apelativo de "gueniza" (escondrijo) y los fragmentos reunidos recibían el nombre de "chemot" (nombres). Suponíase que las letras albergaban, de una u otra manera, el nombre de Dios, por tanto, estaba prohibido, de modo radical, arrojar los "nombres" o pisotearlos, ni siquiera involuntariamente.

\title{
1.3. La Cábala práctica
}

La Cábala es una ciencia de la vida, caracterizada por la unión de la fuerza visible y del espíritu invisible de la ley. El cabalista es, justamente, el hombre que busca establecer dicha unión. En ese sentido, el Sefer Yetsira, Libro de la Creación, constituye el primer intento de sistematizar la teología especulativa hebrea. Para ello, reconociendo la existencia del Dios único, muestra y demuestra que, entre la variedad y la multiplicidad, hay una armonía y una unidad que no pueden más que derivar de un "Coordinador Único". Empero, a diferencia de la Biblia, el Yetsira evidencia que la deidad suprema crea el universo, no a partir de la nada, antes bien desde Él mismo (a partir del Ein-Sof). Dios es la materia y, al mismo tiempo, la forma del Universo. El está en el fondo de todas las cosas y todo existe en él. De este texto, podemos extraer lo siguiente:

- La creación se realizó según la tríada sefar/sippur/sefer, es decir, la fórmula esencial utilizada por el Creador. La primera, sefar, significa la cantidad medida, el número, la base de armonía y el orden superior de las cosas. Sippur significa la emisión de la palabra, la voz, el Verbo del Creador, por el cual las cosas son. Finalmente, sefer representa la escritura, la palabra, la letra escrita, en suma, el Libro.

- Treinta y dos son los senderos por los cuales la suprema unidad divina actuará en la tierra: los diez sefirot o emanaciones divinas y las veintidós letras sagradas del alfabeto hebraico. Los sefirot distinguen los matices de la calidad y constituyen los veintidós canales que, en el Árbol de la Vida, unen entre sí los diez sefirot. De igual forma, cada una de estas veintidós letras tendrían una correspondencia con una carta del tarot de los Arcanos Mayores. 
- Las veintidós letras hebreas representan una serie de actividades humanas, de elementos propios del espacio y el tiempo. Así, por ejemplo, las siete letras dobles del alfabeto hebreo coinciden con los siete planetas, los siete días de la semana y los siete orificios de la cabeza. Las doce letras simples, por su parte, corresponden a los doce signos del Zodíaco, los doce meses del calendario solar y los doce órganos del cuerpo. También existe un nexo entre las letras, ciertos números y determinados colores.

En definitiva, comprenden un conjunto de relaciones entre el macrocosmos y el microcosmos, como podemos apreciarlo en el apéndice No. 1.

Todo el conocimiento que Dios proporcionó a Israel —es decir, a la humanidad- está contenido en la Tora (la Ley). Sin embargo, allí deben distinguirse dos tipos de Tablas de la Ley: las primeras, emanadas del Árbol de la Vida, pero que Israel, por haber adorado al becero de oro, fue juzgado indigno de beneficiarse de ellas; y las segundas, salidas del costado del Árbol del Bien y del Mal, fueron las que Moisés, por mandato divino, dio a su pueblo.

Estas tablas segundas representaban solamente una manifestación fragmentaria de aquella hohma original (sabiduría divina), lo cual impedía que el hombre se sirviera del conocimiento. En consecuencia, para que el cabalista pudiera tener acceso al hohma, debía buscar con gran celo la verdad que yacía oculta detrás de las Escrituras. No obstante, este tipo de Cábala "auténtica" quedó en poder de un grupo reducido de cautos rabinos, mientras que el conocimiento general únicamente alcanzó su faceta puramente esotérica. La magia pudo hallar, con base en el complicado formulismo de los cabalistas, la codificación de palabras, gestos y símbolos necesarios para su ceremonial específico. Transcurrido cierto tiempo, las prodigiosas hazañas de los iniciados en la disciplina consolidaron la confianza en el poder sin límites de la palabra: se decía que un maestro del siglo XV, el rabí Loew de Praga había fabricado una entidad artificial, un Golem, que cobró vida cuando fue escrito sobre su frente de arcilla uno de los nombres secretos de Dios. Con todo esto, la Cábala perdió, en Occidente, su preciosa carga mística y, habiendo abandonado su cauce materno, se entremezcló con todo tipo de doctrina heterodoxa, la cual atribuía al alfabeto sacro una serie de correspondencias, desde los principios universales hasta los procesos alquímicos, sin olvidar el Zodíaco y el Tarot (vid. Anexo No. 1).

Para acercarnos un poco a la Cábala práctica hemos de recurrir a la Gematria, la primera llave, conocida también como la Cábala matemática o aritmética. Consiste en atribuir un determinado sentido a las palabras en función de su valor numérico. Podíase reemplazar así una palabra por otra que poseyese el mismo valor numérico, con lo cual se obtenían ocultos e insospechados sentidos en las Escrituras.

Los hebreos empleaban las letras para representar las cantidades numéricas, es decir, un mismo signo sería letra y número, todo dependía del contexto. Así, la letra aleph constituía el número uno; beth, el dos; ghimel, el tres; etcétera. Entonces, una palabra albergaba un sentido numeral, obtenido de la suma de los valores de las letras que la componían. Y esa cantidad podía ser descompuesta en otra serie de letras, las cuales, unidas, formarían una palabra totalmente distinta de la primitiva. Por ejemplo, en el Capítulo XLIX, versículo 10, del Libro de Génesis ("No se quitará la vara de mando a Judá, ni faltará el legislador de entre los de su generación, hasta que venga Shiloh, el pacífico"). Si sumamos el valor numérico (vid. Anexo No. 2) de la palabra shiloh, se obtiene el mismo número que el constituido por la palabra Mashiah (Mesías): 


$$
\begin{gathered}
300+10+30+6+10=356=\text { shiloh } \\
40+1+300+9+1+5=356=\text { mashiah }
\end{gathered}
$$

Notaricon es la segunda llave cabalística, llamada "la de las siglas": se toma cada letra de una palabra como inicial o abreviatura de otra. De este modo, se construiría una frase con las letras de una sola palabra. Utilizamos este método de manera similar en el sistema de las siglas sociales, políticas o comerciales, cuando reducimos el nombre de una institución a un conjunto ínfimo de letras (O.N.U., O.M.S., U.C.R., O.T.A.N., O.E.A., I.C.E., etc.). Muestra de lo anterior es la palabra Beresit (deletreada en hebreo BRASHTH), primer vocablo del Génesis. Al construir palabras con cada una de las letras como iniciales, los cabalistas judíos obtuvieron diversas frases, tales como: "Bará ruheres samayim, yam, thom", que significa "Creó el Espíritu, la Tierra, los Cielos, el Mar y el Abismo". O bien esta otra: "En el comienzo, Dios vio que Israel debía aceptar la Ley”.

La tercera llave es la Temurá, "de las permutaciones y combinación de las letras". Presumiblemente, es el procedimiento interpretativo de más antigüedad, con respecto a los otros dos. Fue el método más idóneo para descubrir los significados cifrados en los textos sagrados del pueblo hebreo. La Temurá es la base de la Cábala literal, la cual consiste en no tomar las escrituras en sentido literal, sino más bien dilucidar las verdades encerradas en ellas, empresa sólo posible para los iniciados, quienes recurren a procedimientos análogos a las actuales fórmulas criptográficas: separan las letras de una palabra y cambian su orden natural, o bien, trastocan la colocación de las diferentes palabras de una frase. El más célebre y, a la vez, el más sencillo alfabeto críptico es el "atbes" y consiste en sustituir la primera letra de una palabra por la última, la segunda por la penúltima y así subsecuentemente. De esa manera, como ilustración, el término ADÁN podría ser suplantado por NADA. Siguiendo tales premisas, los cabalistas están absolutamente convencidos de que la totalidad -o por lo menos la mayoría- de los nombres sagrados son, en realidad, fórmulas herméticas que, una vez descifrado su genuino sentido, nos pueden conceder poderes incalculables y extraordinarios.

\section{El Golem mágico}

Durante el Medioevo, en Alemania, emergió un cardinal movimiento místico, el jasidismo. Poco se sabe acerca del legendario fundador de esta corriente cabalística, el rabino Samuel, hijo de Kalynamus de Spiro, pero su testamento espiritual es célebre gracias al texto nominado Sefer Jasidim (Libro de los piadosos), escrito por su sobrino, el gran Eleazar de Worms.

Esta obra aparece fuertemente estigmatizada por el idealismo mesiánico, común entre las agrupaciones sefarditas: equipara al cabalista con un protector de las masas más pobres e incultas, a las cuales redime con sus poderes taumatúrgicos y sobrehumanos. Desde este punto de vista, Guy Casaril ha establecido un paralelismo entre el santo de Worms y San Francisco de Asís, puesto que ambos personajes suscitaron la misma admiración devota entre las clases menesterosas. Sin embargo, como es habitual en los movimientos cabalísticos, la intención básica del jasidismo pronto fue olvidada y hasta ignorada. Muy pocos seguidores comprendieron la necesaria renunciación a los bienes mundanos y materiales, a los placeres 
y poderes terrenales para poder ofrendar su vida al amor por su Dios. En lugar de esto, la mayoría sólo vio en el jasidismo un poderoso instrumento de dominación mágica. Asimismo, el propio Eleazar de Worms, quizá sin proponérselo, contribuyó a fomentar el prestigio supersticioso de la doctrina, al dar a la palabra una potestad ingente sobre el destino y el mal. En definitiva, a Eleazar se debe el concepto de homunculus o golem mágico, como una culminación prodigiosa de las milagrosas facultades que podían ostentar los iniciados cabalistas.

La creación del golem u hombre artificial está ampliamente explicada e ilustrada en varias recetas del sabio de Worms: una mezcla de letras y prácticas mágicas, destinadas a obtener determinadas experiencias místicas, durante las que el golem cobraría vida autónoma.

\subsection{El homúnculo a través de la historia}

El principio mítico de la creación de una entidad artificial no es originario del jasidismo medieval, antes bien se remonta a las más añejas tradiciones judaicas, con base en el Libro del Génesis $(1,24)$ : "Dijo todavía Dios: Produzca la tierra animales vivientes en cada género, animales domésticos, reptiles y bestias silvestres de la tierra, según sus especies. Y fue hecho así”. Los cabalistas interpretaron aquí la confirmación indirecta de la posibilidad real de una animación de materia vil, no habiendo recibido el hálito inicial de vida. Por su parte, los traductores de la Biblia adjudican el apelativo de "golem" al mismo Adán, antes de que le fuese insuflada el alma y, principalmente, antes de que hablara.

Llama la atención sobremanera el hecho de que casi todas las generaciones se hayan enfrentado con el dilema de la generación del ansiado hombre artificial. Esto podría tener un asidero al mirar a este sosia como un potencial puente entre el conocimiento y la malicia, o bien, como un símbolo de la audacia de Prometeo latente en el hombre. Además, si Dios creó el cosmos mediante el Pensamiento y el Verbo con sus auxiliares (las letras y los números), el hombre podría ser poseedor de los medios, realizar toda especie de prodigios y magnificencias, obviamente en una escala menor a la del gran Arquitecto, pero que modificarían la naturaleza interior. En este sentido altivo, el ser humano, sabedor de las leyes y las escrituras, generaría creaciones artificiales con la combinación adecuada de los 72 signos alfabéticos del nombre de Dios, siguiendo las instrucciones del libro cabalístico del Yetsira. Jacob Grimm, en su Diario para solitarios, ofrece una excelente descripción del proceso creacional del golem:

Los judíos polacos, después de pasar unos días orando en voz alta y ayunando, moldean la figura de un hombre, en barro u otra masa viscosa, y cuando pronuncian sobre ella el nombre cabalístico de Dios, éste habrá de cobrar vida. Hablar, desde luego, no puede y entender, apenas lo que se le habla u ordena. Le llama golem y lo utilizan como criado para ocuparse de cualquier trabajo doméstico. En su frente figura escrita la palabra "emeth" (verdad), se desarrolla día tras día y llega a hacerse más robusto y fuerte que los demás moradores de la casa, a pesar de haber sido tan diminuto al principio. Les empieza a infundir espanto y entonces le borran la primera letra del anagrama que lleva en la frente, de manera que sólo queda la voz "meth" (está muerto); al ocurrir esto se desploma el simulacro y se deshace en polvo. Sucedióle una vez a un judío esto: su golem llegó a hacerse tan alto y, por negligencia, aún así, lo dejó crecer más, hasta que llegó el momento en el cual ya no podía alcanzarle la frente. Pudo, a pesar de los esfuerzos, borrarle la primera letra, sin embargo, todo el peso de la masa cayó sobre este judío y lo aplastó (Grimm 1967: 76). 
Para escribir esta narración detallada, Grimm se basó en un antiguo relato talmúdico y en las enseñanzas de Eleazar de Worms, según las cuales lo esencial gravita en que los diversos adeptos -siempre más de uno de ellos-, unidos en el ritual del golem, tomasen tierra no trabajada de la montaña, la amasaran en agua corriente y moldearan con ella la figura. Acto seguido, sobre cada uno de los miembros del cuerpo del muñeco se pronunciaban aquellas consonantes que prescribe el Sefer Yetsira (vid. Anexo No. 1). Por último se escribía, sobre la frente de arcilla del futuro individuo, uno de los nombres secretos de Dios y la materia informe del golem se animaría de vida.

Posteriormente a las prescripciones de Eleazar de Worms, se multiplica el alud de "fórmulas" sobre la manera de proceder para la generación del golem. Pero, con el transcurso del tiempo, la cualidad de la idea del homunculus ha experimentado un cambio muy notabie. De ahí que la creación de un ser artificial haya pasado de ser una pericia llevada a cabo por personas piadosas, quienes recurren siempre a la ayuda de Dios, a constituirse en un puro y simple acto de magia negra potenciado por Lucifer.

Otra de las características de estas nuevas recetas es la necesidad, cada vez mayor, de acudir a técnicas más o menos sofisticadas. Parafraseando a Goethe, afirmaríamos que a lo natural apenas le basta el cosmos, lo que es artificial exige espacios cerrados. Así, desde el siglo $\mathrm{XV}$, el uso de alambiques se hace necesario para la elaboración del golem. Este abrazo entre la Cábala y la Alquimia tuvo en el genial Paracelso su mejor exponente y en su Arxidoxia mágica la plasmación de uno de los intentos más audaces de las ciencias ocultas: la faena del homunculus. Más tarde, en el siglo XVII, absolutamente en contra de las antiguas representaciones hebreas, tiene lugar la desviación de la imagen del golem hacia lo amenazador y lo maligno. El hombre artificial se ve dotado de una energía excepcional, es capaz de promover grandes calamidades y posee la fuerza para destruir el universo. Esta concepción, con ligeras variantes, ha perdurado hasta nuestros días. Inclusive, podría pensarse que, siguiendo un curso paralelo al desarrollo creciente de la tecnología, el inconsciente identifica la potencia destructiva de la mecánica con la imagen del golem o, lo que es equivalente, del robot. Esta representación fatídica del homúnculo queda perfectamente puesta de manifiesto en la leyenda del "Gran Rabí Loew de Praga". Según esta, el rabino Loew creó un golem, que, por razones obvias, ayudaba a su amo en distintas labores. Como el día de la fiesta sabática debía de ser guardado con estricta devoción, el rabino convertía en masa al golem, al suprimirle el nombre vivificador que llevaba estampado en la frente. Sin embargo, un día olvidóse de quitar el anagrama. Una noche de viernes, mientras la comunidad se encontraba reunida en la sinagoga para participar en el oficio divino, el golem empezó a rugir encolerizado con todas sus fuerzas: sacudía las cosas y amenazaba con destruir todo lo que se hallara a su paso. Llamaron al rabí Loew, le logró arrancar el anagrama y la criatura cayó al suelo. Ante tal desastre, el rabí no estaba dispuesto a "activar" nuevamente el golem, por lo cual sus restos fueron ocultos en el desván de la sinagoga, donde permanecen allí hasta la fecha. Luego, uno de los sucesores del rabí, el rabino Ezequiel Lamdau, subió para contemplar los despojos de la amenazante criatura y dejó la orden sempiterna de que ningún mortal intentara visitar ese desván, ni siquiera una vez.

Los elementos de este relato persisten en una constante temática, incluso tomando en consideración las varias versiones cinematográficas llevadas a la escena por el expresionismo alemán. De ellas, cabe destacar las dos películas de Paul Wegener en 1913 y en 1917: su acción se desarrolla en Praga y los decorados del ambiente del ghetto sugerían los derrumbamientos masivos, la amenaza latente del golem sobre el que se había perdido el control. De la 
misma manera, es necesario señalar la novela de Gustavo Meyrink titulada precisamente $E l$ Golem (1916). Las tres producciones surgen en el momento en que las fuerzas desarrolladas por la técnica (la Primera Guerra Mundial) parecieran haberse puesto en contra de su creador: el hombre. En relación con la obra de Meyrink, el golem es un espectro terrorífico, el cual cada treinta y tres años se manifiesta detrás de las ventanas de una habitación incomunicada del ghetto de Praga. Además, lleva una existencia sobrenatural sin posible redención.

\title{
2.2. El homúnculo de Paracelso
}

Llamábase homúnculos a las figuras humanoides, no nacidas por el método natural de engendramiento, esto es, fuera del cuerpo de la mujer y de la matriz natural. Para tal tentativa se debía proceder así:

\begin{abstract}
...dejar que el esperma del varón se pudra en una calabaza (alambique), sellada con la suma putrefacción del vientre de un equino durante cuarenta días, a todo el tiempo preciso (sic) hasta que empiece a vivir y a moverse y agitarse, lo cual puede verse fácilmente. Después de un tiempo será de algún modo semejante a un hombre, pero transparente y sin cuerpo. Si ya después de esto, cada día se le alimenta y se le nutre cauta y prudentemente con Arcano de la sangre humana, y durante cuarenta semanas se conserva en perpetuo y constante calor del vientre del equino, se hace después un infante verdadero y vivo, que tiene todos los miembros de un infante que ha nacido de una mujer, pero mucho menor. A éste nosotros le llamamos homúnculo, y tiene que ser educado después con mucho cuidado y diligencia como cualquier otro infante, hasta que se desarrolle y empiece a tener juicio y a entender. Este es uno de los mayores secretos que Dios reveló al hombre mortal y sometido al pecado... (Paracelso, Arxidoxia mágica. En de María 1986: 304).
\end{abstract}

El anterior extracto, nos permite apreciar los nuevos puntos de vista sobre la generación del golem desarrollados en el siglo XVI, los cuales se diferencian sensiblemente de la antigua representación hebrea. Empieza a ser disímil la naturaleza de los materiales de "construcción": los primordiales e idóneos elementos, tierra y agua, han sido sustituidos por el sofisticado semen virile. Por otra parte, el lapso exacto para la consecución de la obra se precisa en Paracelso (cuarenta días), mas no es así en Eleazar de Worms; pero, por las indicaciones, se deduce que no debe ser de duración excesivamente prolongada. Ambos comparten la elaboración de matices mágicos. Paracelso describió, además, un "homunculus cereus", figura de cera, la cual se modela según el deseo de su propietario y a la que se le infunden todas aquellas desdichas que se desean causar a un rival. Este golem no sólo era un fetiche de barro, útil en tanto pudiera sujetar al enemigo al arbitrio de su creador. Por otra parte, al margen de las doctrinas alquímicas del médico de Hohenheim, considerábase al onanismo el responsable del origen de los demonios. Así, pensaban que una de las causas primarias de la génesis de los homúnculos monstruosos era justamente la sexualidad antinatural. En su Philosophia Magna, Paracelso mismo es terminante al atribuir este hecho al propio espíritu de Satanás y afirma: "Pues se sabe que lo que no ha sido concebido en la matriz (útero) por obra natural, tiene inclinación hacia lo monstruoso... no es ya semen, sino materia homunculi" (En de María 1986: 308). En su Liber de Homuncullus, va más allá de este punto al aseverar que los animales frecuentemente comenten sodomía y el semen a veces empleado para estos menesteres -sea la creación de un golem- reviste una mácula originaria de tal envergadura: el 
resultado de esta sodomía es un ser deforme cuyo aspecto causa horror, espanto, turbación, desconcierto. Para ofrecer veracidad a su argumento sostiene que el mulo es el resultado de la "sodomía" entre asno y caballo, el basilisco procede de la unión entre gallo y sapo (asunto mencionado, mutatis mutandi, en Isaías 59, 5). Todos estos monstruos sodomíticos, derivación de acoplamientos tan dispares, tienen algo en común: la carencia de alma. Así las cosas, clara está la disparidad entre hombre y golem (ser artificial), el primero es una entidad provista de alma y el segundo, desprovista de ella.

\subsection{El fundamento cabalístico del golem}

La Cábala se consagra por sí misma como la alianza de la razón universal y del Verbo divino, capaz de conciliar la ciencia con el misterio. Tiene las llaves del pasado, el presente y el porvenir. Por lo tanto, se hace necesario recurrir al Sefer Yetsira para escudriñar el problema de la creación del golem:

Las veintidós letras las ha trazado, recortado, multiplicado, examinado y trocado, y formó con ellas todas las criaturas y todo lo que será creado. ¿Y de qué manera las ha multiplicado? El aleph, con todas; el beth, con todas; el ghimel, con todas, y todas con el ghimel, todas giran en círculo; y así hallamos que salen por doscientas veintiuna puertas; obtenemos que todas las palabras salen bajo un mismo nombre (1990: 4, V. La traducción es nuestra).

Él fijó las veintidós letras-nervios en la esfera, imaginándola parecida a un muro con doscientas veintiuna puertas, y giró las esferas hacia delante y hacia atrás. Para una ilustración pueden servir las letras num, ghimel y tsade, no hay mejor que la alegría y nada peor la pena y la miseria" (1990: 5, V. La traducción es nuestra).

Nótese que los fragmentos anteriores son cimientos fundamentales en la visión cabalística de la creación por intermedio de las letras. Consensus gentium, con respecto a la fabricación del Golem, se habla de 221 puertas; no obstante, esto constituye un aparente error matemático, pues el número exacto de combinaciones es de 231. La cifra de combinaciones de 22 elementos, dos a dos, sin ninguna permutación, viene dado por la fórmula:

$$
\mathrm{N} x-\frac{91}{2}
$$

y si $\mathrm{N}=22$, obtendremos

$$
22 \times \frac{-221}{2}=231
$$

Los cabalistas llaman "puertas" a estas 231 variaciones, porque de cada una de ellas va a emerger uno de los elementos cosmogónicos. Así,.opinan que las 22 letras del alfabeto hebreo son las 22 sustancias primitivas, formadas por la vibración de cada una de las letras. Estas sustancias representan, en el hombre, un órgano; en el espacio, un astro y en el tiempo, un lapso. Luego, estas 22 letras fueron combinadas dos a dos y otorgan a cada combinación una sustancia nueva. 
Los colores manifiestan un fiel reflejo de lo señalado supra. Si suponemos una luz roja, amarilla o azul, tenemos un color primario producido por una vibración determinada (la longitud de onda del rojo es de aproximadamente unos 7.000 ángstrom; la del amarillo es de unos 6.000 ángstrom y la del azul, de 4.500 ángstrom). Si entonces mezclamos dos a dos estos colores primarios, tendremos los restantes colores que, por esta razón, son llamados secundarios. Por ejemplo, el rojo y el amarillo forman el anaranjado (con una longitud de onda de $6.500 \AA$ ); el amarillo y el azul producen el verde (con una longitud de onda de $5.000 \AA$ ). Estableciendo un parangón, hemos de afirmar que las 22 letras del alfabeto hebreo instauran otras tantas puertas capitales o primarias, mientras que su combinación binaria da lugar a otras 231 puertas secundarias.

Con base en lo precedente, Eleazar de Worms elaboró sus celebérrimas recetas en las cuales indicaba que uno de los mayores peligros de aquel hacedor de homúnculos era el de equivocar el orden estricto en el que debían ser recitadas las 231 variaciones alfabéticas. La inversión del precepto conllevaba la desintegración retrógrada, hasta el estado de polvo, del golem, cuando apenas estaba despuntando la vida en él. Este hecho se debe a una circunstancia ya expresada en el extracto del Sefer Yetsira, párrafos atrás, concretamente en la expresión "giró hacia delante y hacia atrás", en lo relativo a las permutaciones de las combinaciones. Veamos. Consideramos la combinación de las tres letras num, ghimel y tsade, enunciadas en el orden citado, evidencian "alegría" - en hebreo-, pero al invertir el orden (tsade, ghimel y num) representa lo opuesto, "pena" y "dolor".

Volviendo a Eleazar, él recomienda que el acto de la creación del golem debe ir acompañado de una determinada técnica de respiración y unos movimientos adecuados de cabeza o de algún otro miembro del cuerpo. Todo lo cual comporta unos ciertos rasgos, pues los errores habrán de volverse en contra del propio autor, el rabino.

\section{Consideraciones postreras}

Vistas las reflexiones de Paracelso, un homúnculo habrá de transformarse en un gigante, apto para la devastación o la degradación. Esta misma idea fatalista guió a los directores cinematográficos a asimilar al golem, el monstruo en rebeldía, como un actante y un ejecutor del pánico colectivo. El crítico Kracauer lo define así: el homúnculo, el ser sin alma, enviado del diablo. Visto desde esta perspectiva, el golem acaba por convertirse en un dictador, que sólo busca la venganza y que, al perseguir la aniquilación, tiene como fin y como medio la violencia, dada su naturaleza maléfica.

Pese a lo anterior, podemos homologar al golem, habiendo nacido de una experiencia mística, con un doppelgänger (literalmente, una forma de espectro que hace su aparición cuando el cuerpo físico se encuentra ausente, en un lugar distante; pero aquí contextualicémoslo con la figura de un "doble", un "otro yo"). Sería un reflejo, una muy baja forma del rabí, su creador. Este doble le permitiría al mago-rabino percibir y descubrir así sus propias fuerzas maléficas, exorcizarlas y evolucionar hacia el camino de la redención, en una especie de proceso de autopurificación. El mago está en una postura de privilegio, el doppelgänger es ahora el uno inferior, que puede ser redimido al aceptar sus faltas, al absorberlas y al corregir el desequilibrio. Con un autoexamen, el mismo golem de uno es creado y, a la vez, confrontado. 
Siguiendo tal razonamiento, el camino espiritual, junto con la más alta iniciación del alma, tendrá su seguimiento a lo largo del ciclo iniciático, producto de la depuración del ser y del conocimiento del yo verdadero. Hipotéticamente, cada estadio tendría su golem, sea en el ejercicio del Pilar Medio, sea al pronunciar la meditación sefirótica. Es decir, un golem es creado con el objetivo de ser redimido.

En una escala más amplia, se dice que el golem es símbolo del alma colectiva del pueblo judío, cuyo progreso expresaría supuestamente el estado de la humanidad: el Golem sería pues la manifestación de toda la humanidad, la encarnación de la condición corriente y ordinaria del mundo. Incorpora al individuo, a las comunidades, las naciones, la naturaleza y toda la ecología del planeta. El Golem se levantó, antes que la humanidad -su creadora-, para inquirir sobre la redención. Esta óptica del cosmos, presentaría al género humano no sólo el bien sino el mal y el significado por el cual el mundo merece ser mejorado y hasta liberado de su estado presente. Golem y hombre comparten un origen y un destino comunes: proceden de la tierra y a ella retornarán, como versa el salmo 82 (vv. 6-7):

Vosotros sois dioses, y todos vosotros hijos del Altísimo; pero como hombres moriréis y como de los príncipes caeréis.

\section{Bibliografía}

Bompiani. 1967. Diccionario literario. Barcelona: Montaner y Simón.

Brandon, S.G.F. 1977. Diccionario de religiones comparadas. Madrid: Cristiandad.

Castiglioni, Arturo. 1972. Encantamiento y magia. México: F.C.E.

Chevalier, Jean. 1988. Diccionario de símbolos. Barcelona: Herder.

Chinchilla Sánchez, Kattia. 1991. "Entre el Adán y el Golem, a propósito de un poema de Jorge Luis Borges". Revista de Filología y Lingüística. XVII (1-2): 63-71.

Cirlot, Eduardo. 1985. Diccionario de símbolos. Barcelona: Labor.

Cordoberg, Moisés. 1977. Pardes Rimmonin o Jardín de los Grandes. Barcelona: Planeta.

Grimm, Jacob. 1967. Diario para solitarios Buenos Aires: Losada.

Life goes to movies. 1975. Boston: Time-Life Books.

María, Constantino de. 1984. Enciclopedia de la magia y de la brujería. Barcelona: De Vecchi.

Masson, Hervé. 1975. Manual-diccionario de esoterismo. México: Roca. 
Reuben, Leaf. 1976. Hebrew Alphabets, 400 B.E. to Our Days. New York: Bloch Publishing. Sagrada Biblia. 1977. New York: Grolier.

Sefer Jasidim. 1992. New York: Jerusalem Books.

Sefer Yetsirah. 1990. New York: Jerusalem Books.

Zohar: The Book of Splendor. 1982. Chicago: SCB Distributors.

Zukerwav, Chaim David. 1996. As 3 Dimensôes Kabalá. Essência, Infinito e Alma. Río de Janeiro: Sêfer. 


\begin{tabular}{|c|c|c|c|c|c|c|c|c|c|c|c|c|c|c|}
\hline \multirow{8}{*}{ 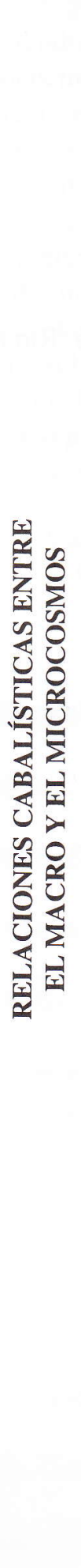 } & 放题 & 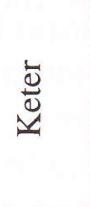 & 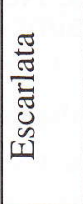 & & 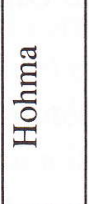 & $\stackrel{\mathscr{2}}{\cong}$ & 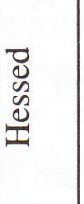 & & & & & $\underset{0}{\stackrel{\pi}{\Xi}}$ & 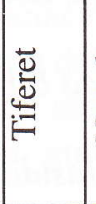 & 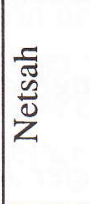 \\
\hline & $\begin{array}{l}\frac{x}{0} \\
\frac{1}{0} \\
0\end{array}$ & 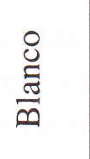 & fo & 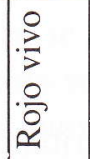 & $\frac{\frac{\pi}{0}}{\frac{0}{0}}$ & 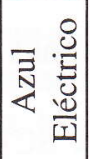 & 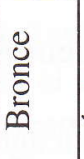 & 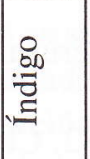 & 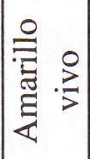 & 总 & $\begin{array}{l}\text { o } \\
\text { कू } \\
\text { z }\end{array}$ & $\begin{array}{l}\text { 总 } \\
\text { 莺 } \\
\text { 宗 }\end{array}$ & 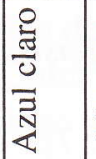 & 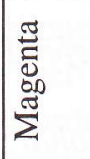 \\
\hline & 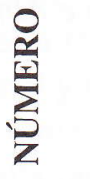 & - & 总 & 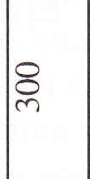 & $\sim$ & $m$ & $\nabla$ & ્ㅗ & $\infty$ & ৪্ণ & 8 & $\ln$ & 0 & $r$ \\
\hline & 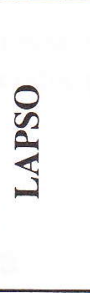 & 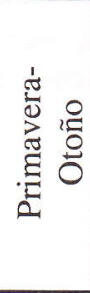 & 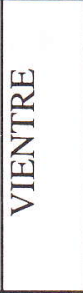 & 总 & 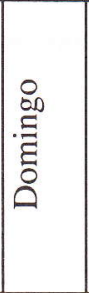 & 岕 & 离 & 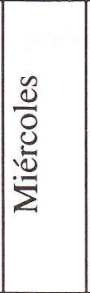 & \begin{tabular}{|l}
0 \\
0 \\
0 \\
0 \\
$\Xi$
\end{tabular} & 岕 & 苞 & 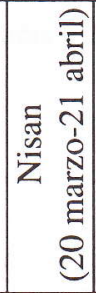 & 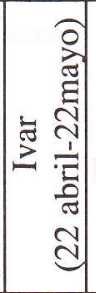 & 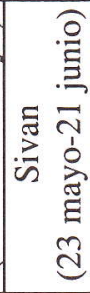 \\
\hline & 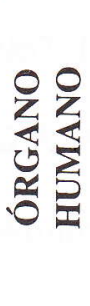 & $\underset{\substack{0 \\
\text { 年 }}}{0}$ & 㥑 & $\frac{\pi}{N}$ & ర্ঠি & 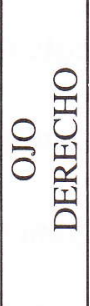 & 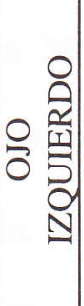 & 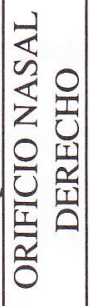 & 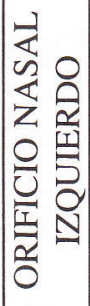 & 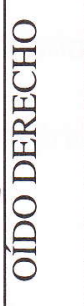 & 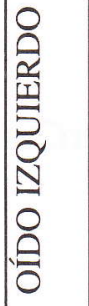 & 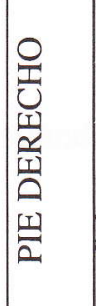 & 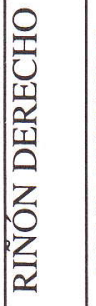 & 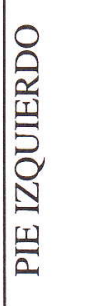 \\
\hline & 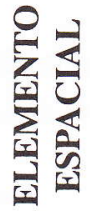 & 紱 & 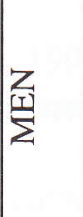 & 足 & 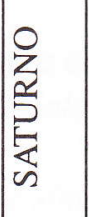 & 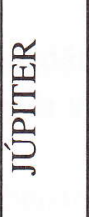 & 党 & 官 & $\sum_{\substack{2 \\
>}}^{2}$ & 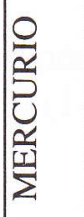 & 苾 & 穽 & 尽 & 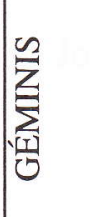 \\
\hline & 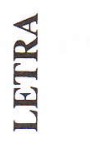 & $\begin{array}{l}\frac{\pi}{2} \\
\text { 自 }\end{array}$ & & 壹 & 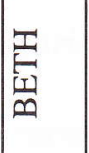 & $\underset{⿱ ㇒}{\mid}$ & 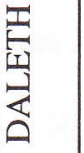 & 焉 & 䛼 & $\begin{array}{l}\frac{1}{5} \\
\frac{1}{10} \\
\frac{1}{2}\end{array}$ & $\underset{\mathbb{Z}}{\stackrel{D}{I}}$ & 堅 & $\underset{>}{\stackrel{2}{2}}$ & 孞 \\
\hline & & 选寒 & 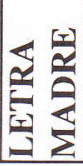 & 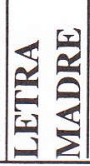 & 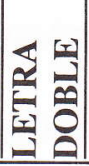 & 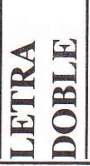 & 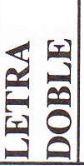 & 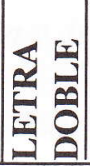 & 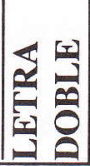 & 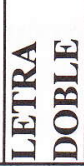 & 选突 & 䚄 & 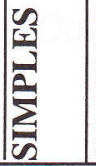 & 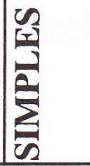 \\
\hline
\end{tabular}




\begin{tabular}{|c|c|c|c|c|c|c|c|c|c|}
\hline 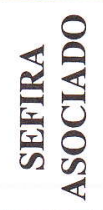 & 몸 & 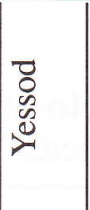 & 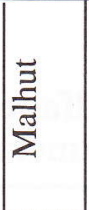 & & & & & & \\
\hline $\begin{array}{l}\frac{x}{0} \\
\frac{1}{0}\end{array}$ & $\begin{array}{l}0 \\
.00 \\
.00 \\
\Xi\end{array}$ & $\frac{0}{2}$ & 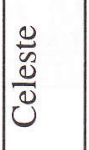 & $\frac{\pi}{\frac{\pi}{0}}$ & 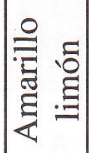 & 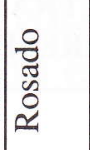 & 㺃 & 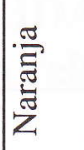 & $\bar{Z}$ \\
\hline 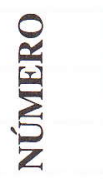 & $\infty$ & $a$ & 으 & 尺 & in & 8 & $\stackrel{R}{2}$ & శ̊ & 8 \\
\hline 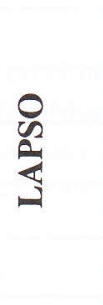 & 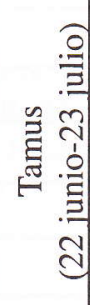 & 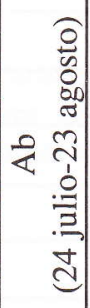 & 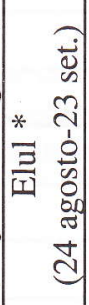 & 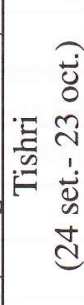 & 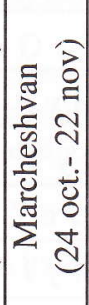 & 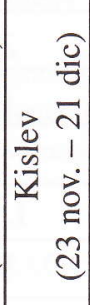 & 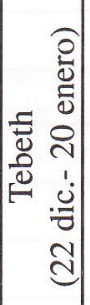 & 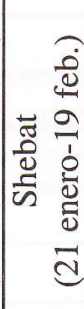 & 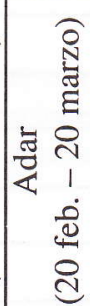 \\
\hline 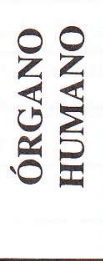 & 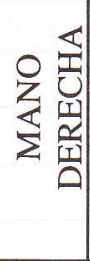 & 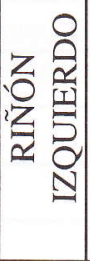 & 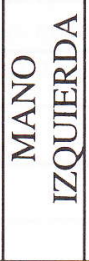 & 先 & 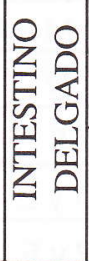 & 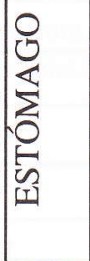 & 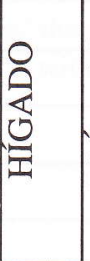 & 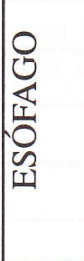 & 命 \\
\hline 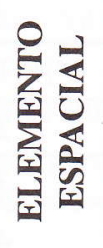 & 总 & 임 & \begin{tabular}{l}
0 \\
0 \\
$\ddots$ \\
\hdashline
\end{tabular} & 这 & 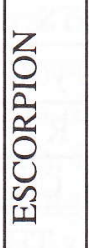 & 会 & 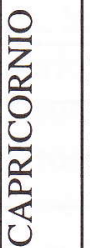 & 晃 & $\begin{array}{l}\tilde{\omega} \\
\tilde{2} \\
\tilde{2}\end{array}$ \\
\hline \multirow[t]{2}{*}{ 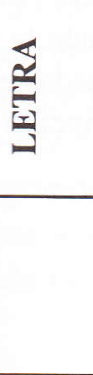 } & 鴶 & 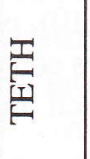 & 을 & 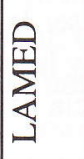 & 洨 & $\sum_{\infty}^{|c| c}$ & 怒 & 崩 & $\frac{\pi}{2}$ \\
\hline & $\sum_{\substack{n\\
}}^{\infty}$ & 䛓 & 产 & 高 & 产 & 量 & 产 & 盗 & 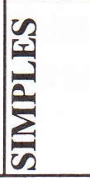 \\
\hline
\end{tabular}




\section{APÉNDICE No. 2}

\section{Transcripción aproximada del alfabeto hebreo y sus correspondencias numéricas}

\begin{tabular}{|c|c|c|}
\hline LETRA HEBREA & $\begin{array}{l}\text { LETRAS LATINAS } \\
\text { CORRESPONDIENTES }\end{array}$ & $\begin{array}{c}\text { VALOR } \\
\text { NUMÉRICO }\end{array}$ \\
\hline Aleph & A & 1 \\
\hline Beth & $\mathrm{B}$ y V & 2 \\
\hline Ghimel & $\mathrm{C}$ y $\mathrm{G}$ & 3 \\
\hline Daleth & $\mathrm{D}$ & 4 \\
\hline $\mathrm{He}$ & E y H & 5 \\
\hline Vau & $\mathrm{F}, \mathrm{V}, \mathrm{O}$ y U & 6 \\
\hline Zayin & $\mathrm{Zy} \mathrm{G}$ & 7 \\
\hline Cheth & $\mathrm{H} \mathrm{y} \mathrm{J}$ & 8 \\
\hline Teth & $\mathrm{I} \mathrm{y} \mathrm{T}$ & 9 \\
\hline Iod & $\mathrm{I}, \mathrm{J}$ e $\mathrm{Y}$ & 10 \\
\hline Khaph & $\mathrm{H}$ y $\mathrm{J}$ & 20 \\
\hline Lamed & $\mathrm{L}$ & 30 \\
\hline Men & $\mathrm{M}$ & 40 \\
\hline Num & $\mathrm{N}$ & 50 \\
\hline Samej & $\mathrm{S}$ & 60 \\
\hline Ayin & $\mathrm{OyE}$ & 70 \\
\hline Phe & P y F & 80 \\
\hline Tsade & TS & 90 \\
\hline Caph & $\mathrm{CyK}$ & 100 \\
\hline Resh & $\mathrm{R}$ & 200 \\
\hline Shin & $\mathrm{S}, \mathrm{SH}, \mathrm{CH}$ y X & 300 \\
\hline Thau & T у TH & 400 \\
\hline
\end{tabular}

*Nota: Examinando esta tabla, veremos que, por ejemplo, la t puede equivaler a teth (valor numérico 9) o a la thau (valor numérico 400); la i puede ser la yod (10), pero también la teth (9) y así sucesivamente. El hebreo sólo usa consonantes y las vocales son reemplazadas en la escritura por puntos debajo de las letras. Esta circunstancia hace difícil una transcripción exacta a una lengua con alfabeto latino. 